\title{
Short communication: A comparison of the rate of polyethylene decomposition among Bacillus spp., Pseudomonas spp., and Escherichia coli bacteria
}

\author{
MICHAEL PHILANDER ${ }^{1, \vartheta}$, PAULETTE RAGOBEER ${ }^{2, \bullet \bullet}$, RUTH DANIEL $^{3, \bullet \bullet \bullet}$ \\ ${ }^{1}$ University of Guyana, Turkeyen Campus, Greater Georgetown, Guyana. Tel.: +592-222-4573, \\ "email: michaelphilander95@gmail.com, vv paulette.ragobeer@gmail.com \\ ${ }^{2}$ Department of Biology, Faculty of Natural Sciences, University of Guyana, Turkeyen Campus, Greater Georgetown, Guyana. \\ Tel.: +592-222-4573, ${ }^{* \cdots}$ email: ruthdaniel2k@ hotmail.com
}

Manuscript received: 4 January 2019. Revision accepted: 10 April 2019.

\begin{abstract}
Philander M, Ragobeer P, Daniel R. 2019. Short communication: A comparison of the rate of polyethylene decomposition among Bacillus spp., Pseudomonas spp., and Escherichia coli bacteria. Nusantara Bioscience 11: 97-100. This study did a comparative analysis of the rate of polythene plastic decomposition among three species of bacteria namely, Bacillus spp., Pseudomonas spp., and Escherichia coli. The three bacterial species were cultured and grown in 2-liter polyethylene terephthalate bottles with nutrient broth separately in triplicates along with a control that did not include any bacteria. These bottles were left undisturbed at room temperature for three months (92 days) after which the containers were subjected to sterilization. Plastic weights were taken using an electronic scale and compared with original values. From the results, it showed that in the three months there was a relatively large amount of degradation that occurred. Bacillus spp. and E.coli bacteria yielded similar results and moved at a rate faster than the Pseudomonas spp., A daily rate for each bacterial species was calculated and a predictive figure based on rates was made. If the rates remained constant there would be total degradation of the polyethylene plastics by the Bacillus spp., E. coli and Pseudomonas spp., in 11.45, 11.45 and 12.35 years respectively. This is a significant finding since in nature plastics can take hundreds of years to decompose.
\end{abstract}

Keywords: Bacillus, Escherichia coli bacteria, polythene decomposition, Pseudomonas

\section{INTRODUCTION}

Plastics, since their initial widespread introduction to international markets during the 1970 s, have taken a major toll on our environment. Since the 1970s, the plastics have evolved in a significantly negative way with respect to how they are handled in the environment as they have become thin, single-use polythene bags. More than 1 billion singleuse plastic bags are given out free of charge every day. Most of these plastics, due to their most times single use, are discarded indiscriminately in places where they lead to significant harm. These places include oceans, forest floors, drainage canals, and animal habitats. Many of the areas in which they are dumped do not contain any means for their decomposition and hence the plastics lie there for years without being removed (Beans 2013).

For this research polyethylene plastic was used. This is the most common plastic type in the world and is used to make shampoo bottles, grocery bags, children toys bulletproof vest and many other widely used items. It is one of the many polyolefin plastic polymers. Polyolefins are synthetic resins made by polymerization of olefins. These Olefins are made up of Hydrogen and Carbon (Hoiberg 2010). The molecule of polyethylene composes of a long chain of carbon atoms attached to 2 hydrogen atoms. These chains can be linear (straight chains) or complexed where several branching occurs. The plastic based on its structure tends to manipulated in various ways depending on the purpose it is being used for (Polymer Science Learning Center 2019). In recent years there has been a major push to find methods of decomposing plastics at a faster rate due to the many negative effects of them in nature and their overall aesthetics. Many researchers have gone on to create super bacteria and other enzymes to try to reduce the plastic presence in a faster. Some solutions may be similar than one may think. One solution is to compare the rates of bacteria already known to decompose plastics and compare their rates of decomposition. Attaining this could potentially lead to manipulation of their concentration to find an efficient way to decompose plastics.

This research was aimed at comparing the rates of different bacterial species. This was done to see which bacteria can fastest decompose the plastics to facilitate bioremediation work on the plastics that seem to be colonizing not only our lands but also our oceans. This work also sought to build on previous work done by Nanda et al. (2010) when he compared the decomposition of polythene plastics among strains of Pseudomonas taking from different locations. There was a need to find out whether other bacterial species could be as effective or even more effective than Pseudomonas spp., under the same condition. Usha et al. (2011) also did some amount of work on decomposition of polythene plastics to investigate which species of bacteria could be associated with decomposition. The efficiency of the different bacteria was 
also identified. From this literature, the potential bacterial species that would've been used for the research were determined. Availability of some of the species was a problem, hence there were only three used. In the future, more work similar to this project should be done to determine which bacterial species will decompose the fastest. Using the bacteria in a controlled and concentrated environment could help us quickly remove polythene plastics in a fast and effective way.

The objectives of this research were: (i) To identify which species of bacteria can decompose polythene plastics the fastest among Bacillus spp., Pseudomonas spp., and E. coli. (ii) To determine the rate of bacterial decomposition among the species and compare it to the time taken in nature. (iii) To examine the condition of the plastics at the end of the experiment.

\section{MATERIALS AND METHODS}

\section{Sterilization and preparation}

Using a pre-test-post-test only experimental design, initially, 12 2-liter polyethylene terephthalate bottles were sterilized by initial washing and were placed under a UV-c lamp for 30 minutes. Polyethylene plastic bags were then weighed with a digital scale. The bags were then observed and photographs of their initial state were taken to be used as a basis of comparison. The twelve plastic bags were placed in 1 bottle; each of the bags and bottles were again subjected to sterilization by UV light.

\section{Bacterial and broth preparations}

A nutrient broth of $1600 \mathrm{ml}$ per bottle was prepared using a standard concentration of 25 grams per liter and sterilized by autoclaving at $121^{\circ} \mathrm{C}$ for 15 minutes. After autoclaving, the broth was left to cool and subsequently added to the bottles with plastics. McFarland standards to represent $3.0 \times 10^{-8} \mathrm{CFU} / \mathrm{ml}$ of Pseudomonas spp., Bacillus spp., and Escherichia coli were then made in triplicates and were left in their saline solutions in test tubes. These McFarland standard solutions were then added to a bottle while maintaining stringent microbial practices along with a triplicate where no bacteria were added. This is a modification of the Winogradsky column similar to Churchill (2012) but the soil component was removed so as to compare rates of selected bacteria. The bottles were left for a 3-month period at room temperature.

\section{Collection of results}

After the 3-month period had elapsed the bottles were subjected to sterilization. The plastic bags were then removed and rinsed with $70 \%$ ethanol air-dried and weighed again with a digital scale. Observations along with photos were then taken to compare with the initial condition of the plastics.

\section{RESULTS AND DISCUSSION}

The use of bacteria was found to be a method to decompose plastics due to degradation of paraffin that are saturated hydrocarbons similar to the polythene plastics (Jen-hou and Schwartz 1961). The bacteria use the polythene as a natural carbon source and follow a complex path where they use the carbon for some amount of energy. The use of the carbon which is transformed into energy is what causes the loss of mass in the plastics as seen in the experiment. Plastic biodegradation by certain enzymatic systems also leads to the breaking of the polymer into oligomer and monomers or further converted to organic intermediates like acids, alcohols, and ketones (Arutchelvi et al. 2008). The oligomer and monomer formation are what lead to the production of methane gas along with other molecules as by-products. These cleaved products are absorbed by the microbial cells where they are metabolized. Carbon dioxide and water are formed after aerobic metabolism (Starnecker and Menner 1996), while anaerobic metabolism results in carbon dioxide, water, and methane as the end products, respectively ( $\mathrm{Gu}$ et al. 2000). The bacteria used in the project were capable of respiring both aerobic and anaerobic. A manure scent coming from the bottles could have been an indication of the production of methane by the microorganisms. Methane gases would be present due to the break down of the Carbon and Hydrogen chains that make up the polyethylene molecule. When the bonds have broken the carbons on the chain will be removed this would then lead to the formation of $\mathrm{CH}_{4}$ because the Hydrogen will form stable bonds with the liberated carbon. Further evidence of this breaking of the carbon chain can be seen by inspection of the plastics. As shown below the plastics were left discolored and there was the presence of holes.

Table 1. Results representing the bacterial decomposition of the polythene plastics

\begin{tabular}{lcccccc}
\hline \multicolumn{1}{c}{ Bacteria } & $\begin{array}{c}\text { Cell density used } \\
\left(\mathbf{1 x 1 0}^{\mathbf{8}} \mathbf{C F U / m L )}\right.\end{array}$ & Sample 1 & Sample 2 & Sample 3 & Average & Average loss \\
\cline { 3 - 7 } & & 2.512 & 2.498 & 2.498 & 2.502 & \\
New plastic & 3.000 & 2.442 & 2.448 & 2.464 & 2.451 & 0.051 \\
Pseudomonas spp. & 3.000 & 2.427 & 2.489 & 2.426 & 2.447 & 0.055 \\
Escherichia coli & 3.000 & 2.448 & 2.395 & 2.498 & 2.447 & 0.055 \\
Bacillus spp. & 0.000 & 2.499 & 2.490 & 2.476 & 2.488 & 0.014 \\
Control (Broth and plastic only) & & &
\end{tabular}




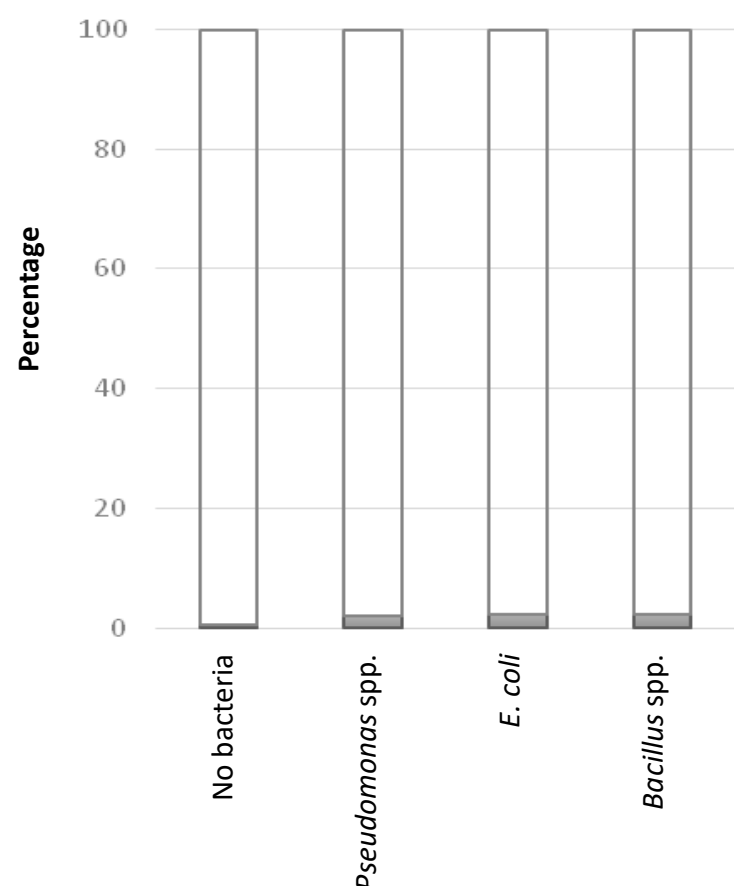

Bacteria used

Figure 1. Graph representing the percentage of weight loss that occurred during the 3 -month period of the experiment
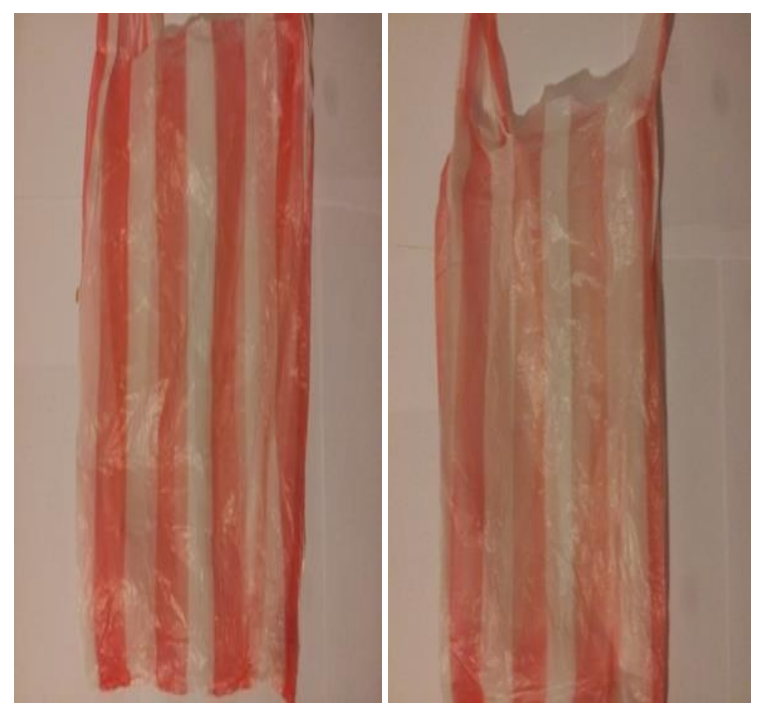

Figure 2. Pictures representing the plastic collected from the control (left) and one acted on by E. coli (right)

The results obtained favored the Bacillus spp., and the $E$. coli which had the same rate of decomposition of plastic. This may be attributed to either one of two factors, the first being the multiplication rate. Both E. coli and Bacillus spp., have a faster rate of multiplication than the Pseudomonas spp. (Todar 2016). This factor contributed to an increased concentration of extracellular enzymes leading to increased rates. Higher concentration would contribute to more surface area of the plastics being degraded by the bacteria which will contribute to the liberation of more carbon molecules from the polyethylene chain. The experiment setup did show that this method is effective. Mean Rate of the Pseudomonas spp., decomposition per day was 5.543 x 10-4 (g/day) Total decomposition would, therefore, be: total mass of plastic $\div$ rate per day which would be equal to $2.5 \mathrm{~g} \div 5.543 \times 10-4$ (g/day) complete degradation would take $4,510.193$ days or 12.35 years

Mean rate of the Escherichia coli decomposition per day was 5.978 x 10-4 (g/day) Total decomposition would, therefore, be: total mass of plastic $\div$ Rate per day which would be equal to $2.5 \mathrm{~g} \div 5.978 \times 10-4$ (g/day) complete degradation would take 4182 days or 11.45 years. Mean rate of the Bacillus spp. decomposition per day was 5.978 x 10 4 (g/day) Total decomposition would, therefore, be total mass of plastic $\div$ Rate per day $2.5 \mathrm{~g} \div 5.978$ x $10-4$ (g/day) complete degradation would take 4182 days or 11.45 years. With the results, it would take about 12 years when compared to the 1000 years in the environment stated by ( $\mathrm{S}$ Kale et al. 2015).

According to Gnanavel the biodegradation of plastic is typically a surface erosion process due to difficulty in penetration of extracellular enzymes into the polymer and so act only on the polymer surface. This process leads to denting as revealed by Nanda et al. (2010). This process may have caused the formation of holes on the plastic and also bleaching of the color. Plastic biodegradation by certain enzymatic systems also leads to the breaking of the polymer into oligomer and monomers or further converted to organic intermediates like acids, alcohols, and ketones (Arutchelvi et al. 2008). These processes explained by Gnannavel can be seen in Figure 2 and 3 where there was discoloration of the plastics. Additionally, some plastics had holes in them.

In conclusion, with the grave concerns surrounding global warming, the use of microbes can be further explored as a means of degrading the plastic waste caused by humans. It is important that further research is done on this topic with other species of bacteria to see which has the fastest rates. From the results obtained we can conclude that following this methodology the Pseudomonas spp., decomposed polythene plastics slower than E.coli and Bacillus spp., The rate of multiplication of the E.coli and Bacillus spp., was responsible for this because in the closed system used, as the concentration of the bacteria increased, the rate of decomposition of plastic increased.

\section{REFERENCES}

Arutchelvi J, Sudhakar M, Arkatkar A, Doble M, Bhaduri S, Uppara PV. 2008. Biodegradation of polyethylene and polypropylene. Indian $\mathrm{J}$ Biotechnol 7: 9-22.

Beans L. 2013. Eco Watch: Silent Killers: The Danger of Plastic Bags to Marine Life. https://www.ecowatch.com/silent-killers-the-danger-ofplastic-bags-to-marine-life-1881783599.html [Aug 30, 2018].

Churchill R. 2012. How to isolate plastic degrading bacteria from soils. https://www.instructables.com/id/How-to-isolate-plastic-degradingbacteria-from-soi/

Gu J D, Ford TE, Mitton D B, Mitchell R. 2000. Microbial corrosion of metals. The Corrosion Handbook. 2 ed. Wiley, New York.

Hoiberg D. 2010. Plastics. Encyclopaedia Britannica Online. http://www.britannica.com/science/plastic. [Aug 30, 2018]. 
Jen-hou L, Schwartz A. 1961. Zum Verhalten von bakteriengemischen gegenüber polyäthylen verschiedenen mittleren Molekulargewichts. Kunststoffe 51:317-320. [Germany]

Kale KK, Deshmukh AG, Dudhare MS, Patil VB. 2015. Microbial degradation of plastic. J Biochem Tech 6 (1): 952-961.

Kathiresan K. 2003. Polythene and Plastics-degrading microbes from the mangrove soil. Centre of Advanced Study in Marine Biology, Annamalai University, Parangipettai, India.

Nanda S, Sahu SS, Abraham J. 2010. Studies on the biodegradation of natural and synthetic polyethylene by Pseudomonas spp. J Appl Sci Environ Manag 14: 57-60.
Polymer Science Learning Center 2019. Polyethylene. https://www.pslc.ws/macrog/pe.htm. [Mar 30, 2019].

Starnecker A, Menner M. 1996. Assessment of biodegradability of plastics under stimulated composting conditions in a laboratory test system. Int Biodeterior Biodegrad 1996: 85-92.

Todar K. 2016. Todar's Online Textbook of Bacteriology. The Growth of Bacterial Populations. http://textbookofbacteriology.net/growth_3.html. [Aug 30, 2018].

Usha R, Sangeetha T, Palaniswamy M. 2011. Screening of polyethylene degrading microorganisms from garbage soil. Libyan Agric Res Cent J Intl 2 (4): 200-204. 